\title{
Duration of inotropic support after left ventricular assist device implantation: Risk factors and impact on outcome
}

\author{
Soren Schenk, MD, ${ }^{a}$ Patrick M. McCarthy, MD, a,b,c,d Eugene H. Blackstone, MD, , d,e Jingyuan Feng, MS, d,e \\ Randall C. Starling, MD, MPH, ${ }^{\mathrm{c}, \mathrm{d}, \mathrm{f}}$ Jose L. Navia, MD, ${ }^{\mathrm{b}}$ Lingmei Zhou, MS, ${ }^{d}$ Katherine J. Hoercher, RN, ${ }^{\mathrm{b}, \mathrm{c}, \mathrm{d}}$ \\ Nicholas G. Smedira, MD, ${ }^{\text {b,c,d }}$ and Kiyotaka Fukamachi, MD, PhD
}

From the Department of Biomedical Engineering, Lerner Research Institute, ${ }^{a}$ the Department of Thoracic and Cardiovascular Surgery, ${ }^{\mathrm{b}}$ the George M. and Linda H. Kaufman Center for Heart Failure, ${ }^{\mathrm{c}}$ the Transplant Center, ${ }^{\mathrm{d}}$ the Department of Quantitative Health Sciences, ${ }^{\mathrm{e}}$ and the Department of Cardiovascular Medicine, ${ }^{\mathrm{f}}$ The Cleveland Clinic Foundation, Cleveland, Ohio.

Received for publication April 8, 2005; revisions received August 31, 2005; accepted for publication Sept 19, 2005.

Address for reprints: Eugene $\mathrm{H}$. Blackstone, MD, Department of Thoracic and Cardiovascular Surgery/JJ40, The Cleveland Clinic Foundation, 9500 Euclid Ave, Cleveland, OH 44195 (E-mail: blackse@ccf.org).

J Thorac Cardiovasc Surg 2006;131:447-54 $0022-5223 / \$ 32.00$

Copyright ( $\odot 2006$ by The American Association for Thoracic Surgery

doi:10.1016/j.jtcvs.2005.09.031
Objectives: Because duration of inotropic support after left ventricular assist device implantation has been recognized as a surrogate for right ventricular dysfunction, we sought to (1) identify its preimplantation risk factors, particularly its association with preimplantation right ventricular dysfunction, and (2) assess its impact on clinical outcomes.

Methods: Between 1991 and 2002, left ventricular assist devices were implanted in 207 patients, exclusive of those receiving preoperative mechanical circulatory support, which precluded measuring right ventricular stroke work. Duration of inotropic support was analyzed as a continuous variable, truncated by death or transplantation, and in turn as a risk factor for these 2 events.

Results: Inotropic support decreased from $100 \%$ on the day of implantation to $57 \%$, $33 \%$, and $22 \%$ by days 7,14 , and 21 . Its duration was strongly associated with lower preimplantation right ventricular stroke work index, older age, and nonischemic cardiomyopathy and was associated $(P<.04)$ with higher mortality before transplantation but not with transition to transplantation. We identified no preimplantation risk factors for right ventricular assist device use because of its relatively infrequent use in this population (18 patients, only 4 of whom survived to transplantation).

Conclusion: Duration of inotropic support after left ventricular assist device insertion is strongly correlated with low preimplantation right ventricular stroke work index. In turn, it was associated with reduced survival to transplantation. Thus, right ventricular stroke work measured before implantation might be useful in decision making for biventricular support, destination therapy, or total artificial heart.

$\mathrm{R}$ ight ventricular dysfunction (RVD) limits the use and effectiveness of left ventricular assist devices (LVADs) as a bridge to transplantation or destination therapy. Identifying the factors anticipating its occurrence is therefore of clinical importance. However, RVD is a clinical diagnosis based on synthesizing a number of factors, rather than a single hemodynamic measurement. Therefore surrogates for RVD have been proposed, but these have limited utility for preimplantation decision making.

For example, right ventricular assist device (RVAD) support is a surrogate for severe RVD after LVAD implantation. ${ }^{1-6}$ Not only is this not known before implantation, it identifies only the extreme of the RVD spectrum. Our clinical impression has been that RVD is an underappreciated problem with serious consequences that is more prevalent than reflected by contemporary use of RVAD support.

Prolonged inotropic support, arbitrarily defined as 14 days or longer, has been used as another surrogate for less severe forms of RVD. ${ }^{5,6}$ It also is a postimplan- 


\author{
Abbreviations and Acronyms \\ LVAD $=$ left ventricular assist device \\ $\mathrm{RV} \quad=$ right ventricular \\ RVAD = right ventricular assist device \\ RVD = right ventricular dysfunction \\ RVSWI $=$ right ventricular stroke work index
}

tation variable; in addition, it has not been explicitly recognized that duration of support is a continuous variable that might be truncated by transplantation and death. Therefore, to better manage critically ill patients with clinically evident RVD and to assist in preimplantation decision making for biventricular support or cardiac replacement, we reexamined the duration of inotropic support as a surrogate for RVD by (1) identifying preimplantation factors associated with it, with particular emphasis on preinsertion right ventricular (RV) stroke work, and (2) assessing its impact on clinical outcomes.

\section{Patients and Methods}

\section{Devices}

The study was confined to implantable LVADs: the 1000 IP HeartMate (1991-1995, n = 56), VE HeartMate (1993-2002, $\mathrm{n}=$ 105), and Novacor N100 left ventricular assist system (1996-1998, $\mathrm{n}=46$ ). Patient selection criteria and management have been published previously. ${ }^{7}$

\section{Patients}

From December 1991 through July 2002, 259 patients underwent LVAD implantation at the Cleveland Clinic as a bridge to transplantation. Fifty-two patients on pre-LVAD extracorporeal membrane oxygenation or other temporary mechanical support devices (eg, Abiomed BVS 5000) were excluded because using these devices precludes accurately measuring hemodynamic components of RV stroke work. Thus, 207 patients were included in this analysis. During support, patients were maintained on the transplantation list. Demographic, medical history, hemodynamic, and laboratory values, and outcomes were extracted from our Unified Transplantation Database, which has been approved for use in research by the institutional review board (Table 1).

\section{Inotropic Support and RVAD Use}

Immediately after LVAD implantation, all patients received inotropes: milrinone, dobutamine, dopamine, or epinephrine, either alone or in combination. Inotropes were weaned off if LVAD flow was sufficient under optimal volume loading $\left(>2 \mathrm{~L} \cdot \mathrm{min}^{-1} \cdot \mathrm{m}^{-2}\right)$ and if stable hemodynamics were maintained without them. Patients were not considered to be on inotropic support if only renal dose dopamine $\left(\leq 3 \mu \mathrm{g} \cdot \mathrm{kg}^{-1} \cdot \mathrm{min}^{-1}\right)$ was administered.

In 18 patients an RVAD was placed for severe clinically evident RVD with persistently low LVAD flow despite high-dose inotropic support.
TABLE 1. Characteristics of patients before left ventricular assist device implantation

\begin{tabular}{|c|c|c|c|}
\hline Variable & $\mathrm{n}^{*}$ & No. & $\%$ \\
\hline \multicolumn{4}{|l|}{ Demography } \\
\hline Female sex & 207 & 30 & 14 \\
\hline Age, y (mean $\pm S D)$ & 207 & & $55 \pm 11.1$ \\
\hline $\begin{array}{l}\text { Body mass index, } \mathrm{kg} \cdot \mathrm{m}^{-2} \\
\quad(\text { mean } \pm \mathrm{SD})\end{array}$ & 197 & & $27 \pm 5.2$ \\
\hline \multicolumn{4}{|l|}{ Medical history and comorbidity } \\
\hline Ischemic cardiomyopathy & 207 & 127 & 61 \\
\hline $\begin{array}{l}\text { Pre-LVAD hospital stay, } d \text { (median } \\
\quad[15 \text { th, 85th percentiles]) }\end{array}$ & 203 & & $6(2,23)$ \\
\hline Prior thoracic surgery & 207 & 97 & 47 \\
\hline $\begin{array}{l}\text { Acute myocardial infarction within } \\
3 \mathrm{~d} \text { before LVAD }\end{array}$ & 207 & 38 & 18 \\
\hline $\begin{array}{l}\text { Ventricular tachycardia or } \\
\text { fibrillation within } 3 \mathrm{~d} \text { of } \\
\text { implantation }\end{array}$ & 207 & 74 & 36 \\
\hline$I C D$ & 207 & 35 & 17 \\
\hline \multicolumn{4}{|l|}{$\begin{array}{l}\text { Preoperative support (within } 3 \mathrm{~d} \text { of } \\
\text { implantation) }\end{array}$} \\
\hline Inotropes & 194 & 194 & 100 \\
\hline IABP & 207 & 157 & 76 \\
\hline Mechanical ventilation & 207 & 99 & 48 \\
\hline \multicolumn{4}{|l|}{ Hemodynamics } \\
\hline $\begin{array}{l}\text { Mean pulmonary artery pressure, } \\
\mathrm{mm} \mathrm{Hg} \text { (mean } \pm \mathrm{SD})\end{array}$ & 204 & & $37 \pm 8.6$ \\
\hline $\begin{array}{l}\text { Central venous pressure, } \mathrm{mm} \mathrm{Hg} \\
\quad(\text { mean } \pm \mathrm{SD})\end{array}$ & 177 & & $18 \pm 6.0$ \\
\hline $\begin{array}{l}\text { Cardiac index, } \mathrm{L} \cdot \min ^{-1} \cdot \mathrm{m}^{-2} \\
\quad(\text { mean } \pm \mathrm{SD})\end{array}$ & 201 & & $1.85 \pm 0.52$ \\
\hline $\begin{array}{l}\text { RVSWI, } \mathrm{mm} \mathrm{Hg} \cdot \mathrm{mL} \cdot \mathrm{m}^{-2} \text { (median } \\
{[15 \text { th, 85th percentiles]) } \dagger}\end{array}$ & 187 & & $90(190-610)$ \\
\hline \multicolumn{4}{|l|}{ Laboratory values } \\
\hline Creatinine, $\mathrm{mg} \cdot \mathrm{dL}^{-1}($ mean $\pm \mathrm{SD})$ & 206 & & $1.75 \pm 0.90$ \\
\hline $\begin{array}{l}\text { Total bilirubin, } \mathrm{mg} \cdot \mathrm{dL}^{-1} \text { (median } \\
{[15 \text { th, 85th percentiles]) }}\end{array}$ & 206 & & $.4(0.8,3.1)$ \\
\hline $\begin{array}{l}\text { AST, } U \cdot \mathrm{L}^{-1} \text { (median [15th, 85th } \\
\text { percentiles]) }\end{array}$ & 174 & & $45(22,200)$ \\
\hline
\end{tabular}

$S D$, Standard deviation; $L V A D$, left ventricular assist device; $I C D$, implantable cardioverter-defibrillator; $I A B P$, intra-aortic balloon pump; RVSWI, right ventricular stroke work index; $A S T$, aspartate transaminase. *Number of patients for whom data are available. $† D e-$ rived from pulmonary artery catheter monitoring, according to the following RVSWI $=(\overline{\mathrm{PPA}}-\mathrm{PCV}) \cdot \mathrm{SVI}$, where SVI was derived from $\mathrm{CI} / \mathrm{HR}$ ( $\overline{\mathrm{PPA}}$, mean pulmonary artery pressure; $\overline{\mathrm{PCV}}$, mean central venous pressure; SVI, stroke volume index; $\mathrm{Cl}$, cardiac index; $H R$, heart rate).

\section{Data Analysis}

Data are summarized as percentages, means \pm standard deviation, medians with 15 th and 85 th percentiles, or $68 \%$ confidence limits equivalent to \pm 1 standard deviation, as appropriate.

Duration of inotropic support. Because duration of inotropic support might be truncated (censored) by death or transplantation, it was analyzed from the time of LVAD implantation until the earliest occurrence of either of these competing events ${ }^{8,9}$ by using nonparametric Kaplan-Meier and parametric hazard function methods. ${ }^{10}$ 


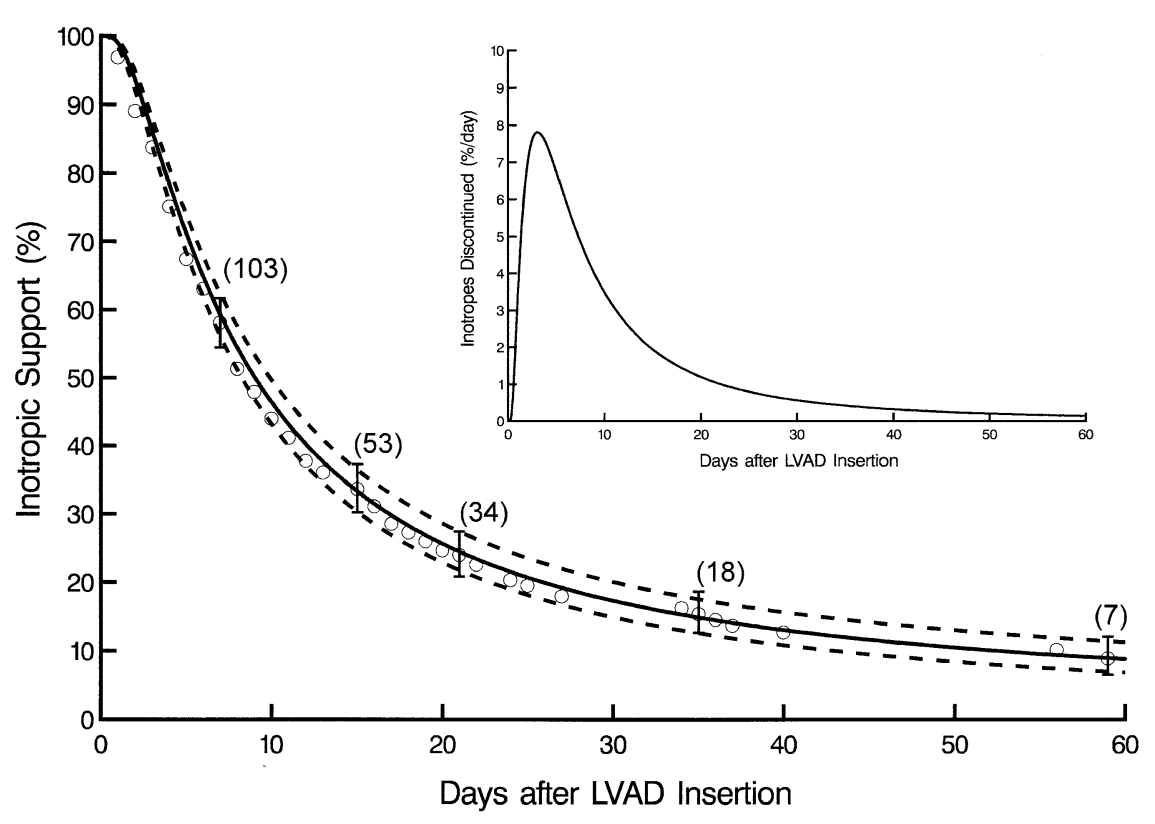

Risk factors for inotropic support and RVAD use. Preoperative risk factors for longer duration of inotropic support were identified by hazard function regression using variables listed in the Appendix, ${ }^{10}$ and for RVAD use by means of logistic regression. Bootstrap bagging (1000 cycles) was used for risk factor selection, ${ }^{11}$ retaining variables in each bootstrap model with a $P$ value of less than .05 . Factors appearing in at least $50 \%$ of model replications were considered reliably identified with a $P$ value of less than .05 .

Of particular importance to this study was pre-LVAD right ventricular stroke work index (RVSWI). It was calculated from preimplantation Swan-Ganz catheter data as follows:

\section{$R V S W I=($ Mean pulmonary artery pressure \\ - Mean right atrial pressure) $\cdot$ Stroke volume index}

Impact of inotropic support on clinical outcomes. Association of duration of inotropic support with death before transplantation and with transplantation itself was assessed in the context of a cross-over phenomenon (technically, a modulated renewal process). ${ }^{12}$ Patients were initially considered as being "on inotropes"; at the time inotropes were discontinued (cross-over), patients were restarted at a new time zero ("not on inotropes"). A variable for duration of previous inotropic support was generated whose value was 0 before inotropic support was discontinued and, thereafter, number of days of support. This allowed us to quantify the association with outcome of inotropic support and its duration.

To depict the influence of inotropic support on survival, we used the cross-over model to simulate 6-month survival for a continuous set of durations of inotropic support. Specifically,

$$
[S(x, I)] \cdot[S(6, N I)] /[S(x, N I)]
$$

where $[S(x, I)]$ is survival at time $x$, on inotropes; $[S(6, N I)]$ is
Figure 1. Duration of inotropic support after left ventricular assist device (LVAD) implantation. Circles represent percentages of patients on inotropic support at the time after implantation (noted on horizontal axis), vertical bars are asymmetric $68 \%$ confidence intervals for these estimates (equivalent to \pm 1 standard error), and numbers in parentheses are patients still on inotropes who have not died, undergone transplantation, or had their device removed after recovery. The solid line, enclosed within dashed $68 \%$ confidence limits, is a parametric estimate; from this is derived the incidence of ending inotropic support (hazard function) shown in the inset. survival at 6 months after LVAD implantation, not on inotropes; and $[S(x, N I)]$ is survival at time $x$, not on inotropes.

\section{Results}

\section{Duration of Inotropic Support}

Complete inotropic support information was available in 194 of 207 patients, all of whom were on inotropes after LVAD implantation. Among patients without RVAD support $(\mathrm{n}=176)$, inotrope use decreased from $100 \%$ on the day of implantation to $57 \%$ and $33 \%$ by postoperative days 7 and 14, respectively (Figure 1); inotropes were most frequently discontinued between 3 and 5 days (Figure 1, inset). Thereafter, decrease of inotropic support became progressively less steep; $22 \%$ remained on inotropes beyond day 21. No sharp cut-off point for duration of inotropic support was evident. Of note, 6 (3.4\%), 9 (5.1\%), and 13 (7.4\%) patients without RVADs were censored before days 14,21 , and 28 because of transplantation or death.

TABLE 2. Preoperative factors associated with longer duration of inotropic support

\begin{tabular}{lccc}
\hline Factor & Coefficient \pm SE & $\boldsymbol{P}$ value & Reliability (\%) \\
\hline Lower RVSWIt & $-0.076 \pm 0.029$ & .008 & 76 \\
$\begin{array}{l}\text { Nonischemic } \\
\quad \text { cardiomyopathy }\end{array}$ & $0.51 \pm 0.19$ & .007 & 51 \\
Older age $\neq$ & $0.79 \pm 0.34$ & .02 & 49 \\
\hline
\end{tabular}

SE, Standard error; RVSWI, right ventricular stroke work index. *Frequency of appearance in 1000 bootstrap resampling analyses. †Exponential transformation. $\ddagger$ Natural logarithmic transformation. 

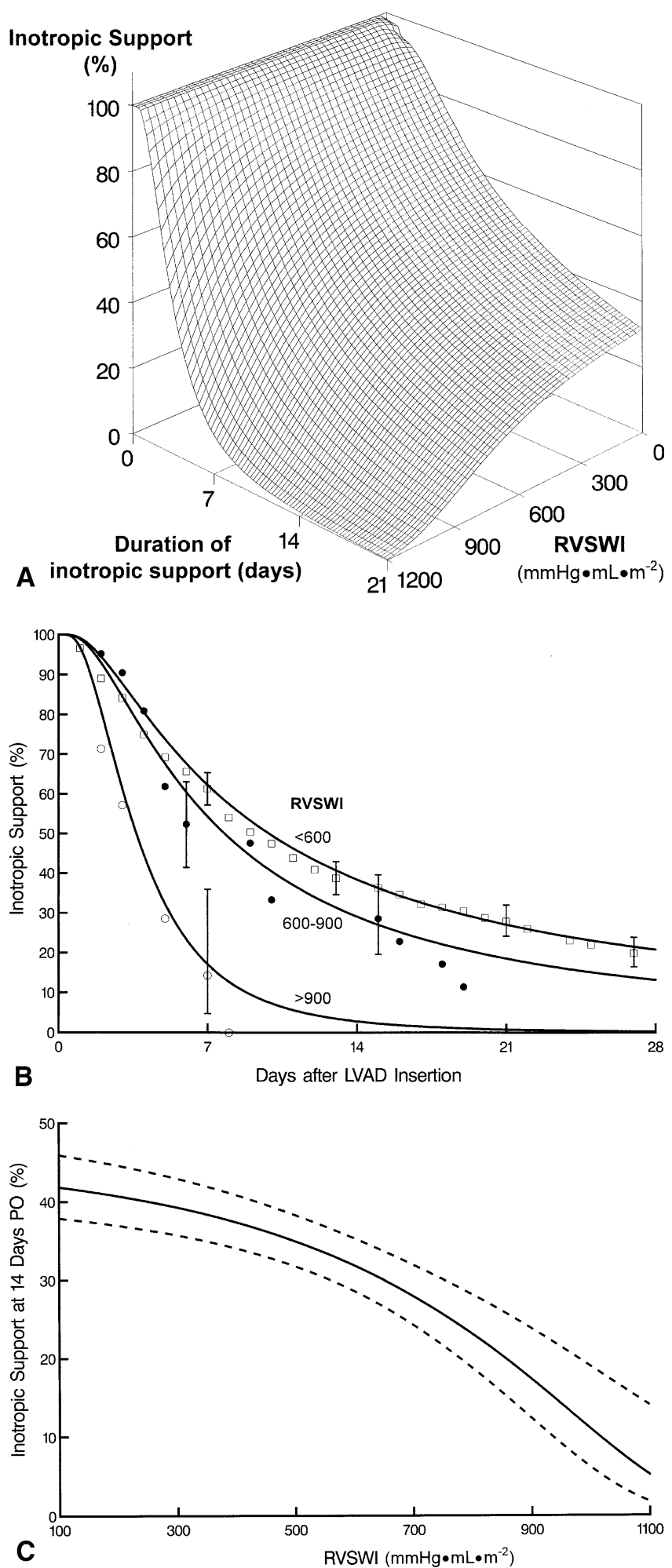

Risk Factors for Inotropic Support

Preoperative factors associated with longer duration of inotropic support included lower pre-LVAD RVSWI $(P=.007$, Table 2 and Figure 2, $A$ ). Of patients with an RVSWI of 600 $\mathrm{mm} \mathrm{Hg} \cdot \mathrm{mL} \cdot \mathrm{m}^{-2}$ or less, $38 \%$ were on inotropes on day 14 compared with $29 \%$ and $3 \%$ of patients with RVSWIs of 600 to 900 and greater than $900 \mathrm{~mm} \mathrm{Hg} \cdot \mathrm{mL} \cdot \mathrm{m}^{-2}$, respectively (Figure 2, B). The majority of patients on inotropic support until day 14 had an RVSWI of about 500 $\mathrm{mm} \mathrm{Hg} \cdot \mathrm{mL} \cdot \mathrm{m}^{-2}$ or less, but duration of support decreased sharply as RVSWI increased (Figure 2, C).

Patients with nonischemic cardiomyopathy, including dilated cardiomyopathy, myocarditis, valvar heart disease, and congenital heart disease, were on inotropic support longer than those with cardiomyopathy of ischemic cause (median, 13 vs 7 days; Table 2). Table 3 provides a synopsis of various median durations of inotropic support associated with RVSWI, cause of cardiomyopathy, and age. At longer durations of support, pre-LVAD RVSWI was lower, patient age was higher, and nonischemic cardiomyopathy was more common. We found no association between duration of inotropic support and sex, body mass index, preoperative central venous pressure, mean pulmonary artery pressure, pulmonary vascular resistance, and variables reflecting renal and hepatic function.

\section{Impact of Inotropic Support on Clinical Outcomes}

A total of 149 patients underwent transplantation, 57 died before transplantation, and 1 was removed from LVAD because of recovery. Survival on LVAD support at 30 days, 3 months, and 12 months was $88 \%, 75 \%$, and $42 \%$, respectively. Risk of death was higher during inotropic support $(P=.006)$. After inotropic support was discontinued, subsequent risk was higher the longer its duration had been $(P=.04$, Figure 3$)$. Figure 4 shows the impact of duration of inotropic support, derived by simulating the difference in 6-month survival if inotropes were weaned sooner rather than later. Patients weaned off inotropic support after day 1 had an estimated survival of $72 \%$ at 6 months; if inotropic support continued until days 10,30 , or 60 , survival decreased to $64 \%, 57 \%$, and $46 \%$, respectively.

Figure 2. Relation between duration of inotropic support and preinsertion right ventricular stroke work index (RVSWI). A, Three-dimensional nomogram. Notice that at high preoperative RVSWI values, most patients are not on inotropic support beyond 7 days, but at low RVSWI values, patients are more likely to be on support for a prolonged period. B, Simple and unadjusted stratification of patients according to RVSWI. Format is as for Figure 1. C, Nomogram as in panel A but solved for prevalence of inotropic support for at least 14 postoperative (PO) days according to RVSWI level. 
TABLE 3. Duration of inotropic support and associated factors

\begin{tabular}{|c|c|c|c|c|c|c|c|c|}
\hline \multicolumn{2}{|c|}{$\begin{array}{l}\text { Inotropic support } \\
\text { duration (d) }\end{array}$} & \multirow[b]{2}{*}{$\mathrm{n}^{*}$} & \multicolumn{2}{|c|}{$\begin{array}{c}\text { RVSWI } \\
\left(\mathbf{m m ~ H g} \cdot \mathbf{m L} \cdot \mathbf{m}^{-2}\right)\end{array}$} & \multicolumn{2}{|c|}{ Age (y) } & \multicolumn{2}{|c|}{$\begin{array}{c}\text { Ischemic } \\
\text { cardiomyopathy }\end{array}$} \\
\hline Median & Range & & Mean \pm SD & Median & Mean \pm SD & Median & No. & $\%$ \\
\hline 3 & $1-5$ & 71 & $470 \pm 270$ & 450 & $55 \pm 11$ & 57 & 50 & 70 \\
\hline 7 & $6-9$ & 38 & $400 \pm 220$ & 315 & $51 \pm 12$ & 51 & 26 & 68 \\
\hline 14 & $10-20$ & 48 & $370 \pm 200$ & 338 & $57 \pm 11$ & 58 & 23 & 48 \\
\hline 27 & $21-45$ & 26 & $360 \pm 170$ & 368 & $58 \pm 9.6$ & 59 & 13 & 50 \\
\hline 69 & $46-185$ & 11 & $390 \pm 210$ & 433 & $55 \pm 10$ & 60 & 5 & 45 \\
\hline
\end{tabular}

RVSWI, Right ventricular stroke work index; $S D$, standard deviation. *Number of patients for whom RVSWI data were available.

Transition from LVAD to heart transplantation peaked around 3 months, with $86 \%$ of patients undergoing transplantation within 6 months. Rate of transition was unrelated to duration of inotropic support, suggesting that patients on inotropes were as likely to undergo heart transplantation as patients off inotropes.

\section{RVAD Support}

An RVAD was placed in $18(8.7 \%)$ patients, 16 within 2 days of LVAD implantation. The other 2 were placed on days 3 and 12 because of respiratory failure followed by severe RVD. In 17 of the 18 patients, high-dose inotropic support for severe RVD preceded RVAD placement. Need for RVAD support was not related reliably to any preoperative risk factor investigated. Survival before transplantation of these 18 patients was $47 \%, 29 \%$, and $22 \%$ at 10, 20, and 30 days, respectively (Figure 5).

\section{Discussion \\ Principal Findings}

Need for inotropic support decreased steadily and continuously after LVAD implantation, although some patients remained on inotropic support for several weeks. Duration of inotropic support was strongly associated with preLVAD RVSWI and was, in turn, associated with increased risk of death before transplantation, although not with earlier transplantation.

\section{Clinical Correlates of RVD after LVAD Implantation}

Several studies have used clinical surrogates of RVD after LVAD implantation, particularly need for RVAD or inotropic support. ${ }^{3,5,6,13}$ Need for RVAD support identifies patients with severe RVD, which is often fatal. We have previously shown an association between poor preoperative RV contractility and subsequent RVAD implantation. In this study we did not find an association between RVAD use and preoperative factors. However, this apparent discrepancy is explained by our excluding 52 patients with preLVAD temporary mechanical circulatory assistance, which was a risk factor for RVD in prior studies. ${ }^{2,14,15} \mathrm{We}$ excluded these patients because pre-LVAD hemodynamic measurements (and specifically RVSWI) with transiently turned off mechanical support were not available in many cases.

We believe that use of inotropic support as a surrogate for less severe RVD requires a more sophisticated approach than simply dichotomizing its duration into short versus long support, as has been done by others. ${ }^{5,6,16}$ Its duration is a continuous variable without a sharp cut-off point with respect to outcomes. Consider the limitations of any arbitrary cut-off duration. With a cut-off duration of 14 days, a patient on inotropic support for 13 days would be classified as not having RVD, whereas one supported for 14 days would be classified as having RVD. This is not a clinically helpful distinction.

\section{Clinical Implications}

Factors associated with prolonged inotropic support identify patients at risk for RVD, delayed rehabilitation, and other complications after LVAD implantation. Although high preoperative pulmonary vascular resistance is a well-recognized risk factor for RVD after heart transplantation ${ }^{17}$ and thus serves as an exclusion criterion, a preoperative predictor of RVD after LVAD implantation useful for decision making has yet to be established. Our results suggest that preoperative RV contractility as reflected in RVSWI, but not preload or afterload, might be one such factor. We now routinely measure RVSWI to assess RV contractility. Perhaps RVSWI will be measured and manipulated as we do pulmonary vascular resistance to assess transplant candidacy. Ideally, a more load-independent measure than RVSWI will be identified to quantify RV contractility. We speculate that such a measure could allow us to better anticipate need for biventricular support versus LVAD support alone.

Current clinical strategies for treating RVD focus on increasing RV contractility with inotropes, providing circulatory support only in cases of severe RVD. For example, we use milrinone, a phosphodiesterase III inhibitor with positive inotropic and vasodilatory effects. ${ }^{18}$ Nevertheless, as found in this study, pharmacologic treatment of RVD is associated with poor survival and thus requires alternative 

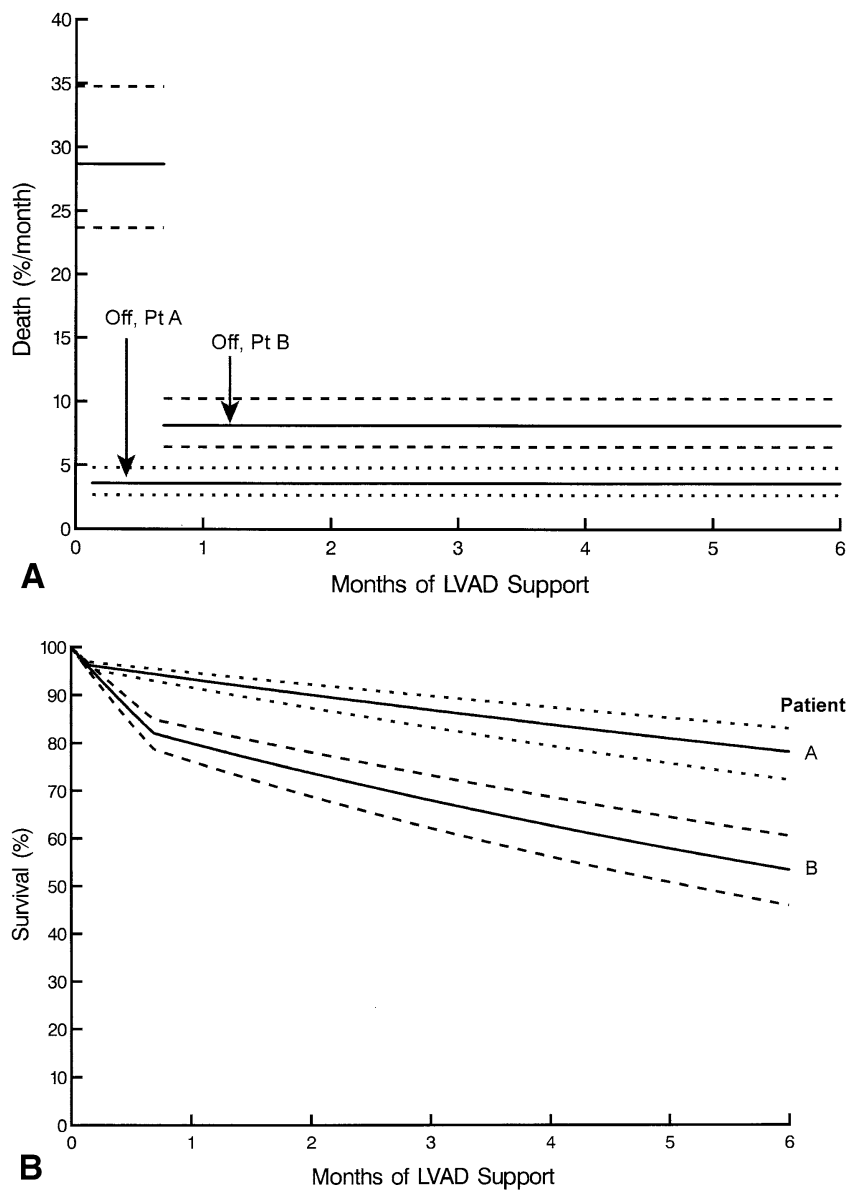

Figure 3. Impact of inotropic support on survival during left ventricular assist device (LVAD) support. A, Hazard functions (instantaneous risk of death) for 2 simulated patients. Patient A was weaned off inotropic support 4 days after LVAD implantation. Hazard decreased nearly 10 -fold. Patient B was weaned off inotropic support 21 days after LVAD implantation. Hazard decreased but not as much as for patient A. B, Survival effect of short (simulated patient $A$ ) versus prolonged (simulated patient $B$ ) inotropic support derived from the hazard functions. Compared with patient $A$, survival of patient $B$ is reduced both by longer exposure to the same high hazard during inotropic support and by higher hazard after discontinuing inotropic support commensurate with its longer duration.

strategies. Although the need for an RVAD is associated with high mortality, this likely reflects current indications. If RVADs were used for less severe forms of RVD, their benefit might become more apparent. Unfortunately, current RVAD use is associated with high risks of bleeding and thromboembolic events, which preclude broader clinical application. Thus, developing blood-compatible implantable RVADs is needed. Cardiac replacement with total artificial hearts might become an alternative for biventricular failure. ${ }^{19,20}$ Results pre-

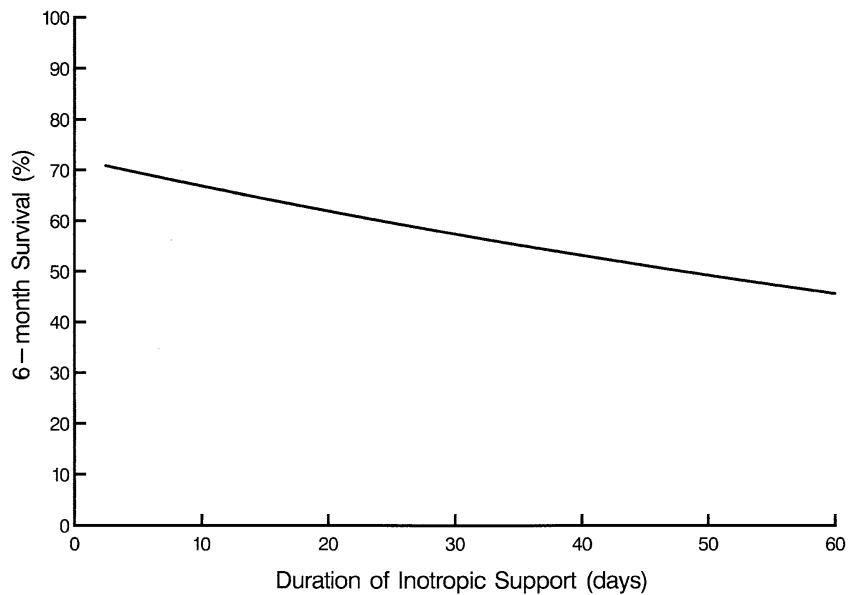

Figure 4. Simulated 6-month survival according to duration of inotropic support expressed on vertical axis as percentage of patients surviving to transplantation. See the "Patients and Methods" section, equation (1), for details of calculation.

sented in this report should be helpful in selecting candidates for these devices.

The most practical use of the knowledge from this study might be in decision making for destination therapy with LVADs alone. If patients remain inotrope dependent, their prognosis is predicted to be poor in the absence of a biocompatible RVAD or other treatment option. ${ }^{15}$ As demonstrated from this study, nonischemic cardiomyopathy, advanced age (likely a large group of these will not be transplantation candidates), and poor preoperative RV function with low RVSWI might prove to be relative clinical contraindications to destination therapy with LVADs.

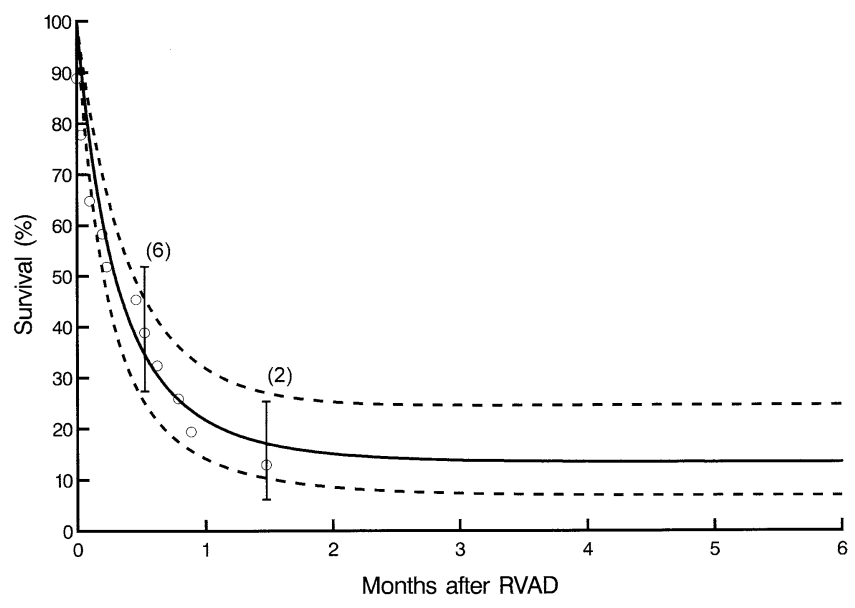

Figure 5. Survival after implantation of a right ventricular assist device (RVAD). Format is as in Figure 1. 


\section{Limitations}

Duration of post-LVAD inotropic support is a recognized surrogate for RVD. Patients might have poor RV function by echocardiography, yet adequate LVAD flow without inotropic support. Unlike others, however, we have considered duration of inotropic support as a continuous variable. A drawback to its use as a surrogate for RVD (either as a dichotomous or continuous variable) is that it is truncated (censored) by both death before transplantation and transplantation itself. We have overcome this problem by (1) use of time-related (censored data) methods and (2) formulation of the data in the fashion of competing risks. ${ }^{9}$ Nevertheless, only $7.4 \%$ of patients without RVADs were censored by one of these competing events within the first postoperative month. Note that these patients might not have been categorized as having RVD if an arbitrary duration of inotropic support were used to define it, even if they were on highdose support and had a poorly contracting right ventricle at the time of early transplantation or death. Thus, we contend that analysis of inotropic support should be time related, with consideration of competing risks.

In identifying risk factors for duration of inotropic support, we considered only preimplantation variables. Certainly, postoperative complications, such as pump malfunction, could also result in need for inotropic support. In addition, many surgeons wean inotropes after LVAD implantation according to device flow and central venous pressure. These postoperative variables were deliberately not considered because our objective was to identify preimplantation risk factors that might help guide device selection. We also did not examine time-varying dosage of inotropic support as a longitudinal end point, only its duration.

Finally, patients receiving pre-LVAD temporary mechanical circulatory support were excluded from this study to ensure accurate assessment of hemodynamics. For this reason, we were limited in some aspects of our analyses that have been covered adequately in our previous studies. ${ }^{3,7}$ Thus, we recognize that pre-LVAD circulatory support is associated with occurrence of severe post-LVAD RVD (need for RVAD), even though we could not reanalyze this in the present study. In our experience, these patients also have preoperative RVD and likely have a low RVSWI, if it could be measured accurately.

\section{Conclusion}

Duration of inotropic support is a valuable surrogate of RVD after LVAD insertion because of its strong association with death before transplantation. However, this relation to clinical outcome is continuous, with no sharp break point, and therefore we recommend abandoning arbitrary durations, such as 14 days, in favor of this continuous relation. Importantly, low pre-LVAD RVSWI is strongly associated with longer duration of inotropic support. Therefore, mea- suring preimplantation RVSWI prospectively might be helpful in selecting candidates more appropriate for biventricular and total artificial heart support than for destination therapy with LVADs.

We thank Tess Parry for editorial advice and the Left Ventricular Assist Device/Transplant Clinical Team, especially Michael Yeager, RN, Tiffany Buda, RN, Kym Zeroske, RN, Sue Vargo, RN, Suzie Hopper, RN, Cathy Zilka, RN, and Deanna Hartman, $\mathrm{RN}$, for outstanding care of patients in the study.

\section{References}

1. Farrar DJ, Hill JD, Pennington DG, McBride LR, Holman WL, Kormos RL, et al. Preoperative and postoperative comparison of patients with univentricular and biventricular support with the Thoratec ventricular assist device as a bridge to cardiac transplantation. J Thorac Cardiovasc Surg. 1997;113:202-9.

2. Frazier OH, Rose EA, Oz MC, Dembitsky W, McCarthy P, Radovancevic $B$, et al. Multicenter clinical evaluation of the HeartMate vented electric left ventricular assist system in patients awaiting heart transplantation. J Thorac Cardiovasc Surg. 2001;122: 1186-95.

3. Fukamachi K, McCarthy PM, Smedira NG, Vargo RL, Starling RC, Young JB. Preoperative risk factors for right ventricular failure after implantable left ventricular assist device insertion. Ann Thorac Surg. 1999;68:2181-4.

4. Oz MC, Argenziano M, Catanese KA, Gardocki MT, Goldstein DJ, Ashton RC, et al. Bridge experience with long-term implantable left ventricular assist devices. Are they an alternative to transplantation? Circulation. 1997;95:1844-52.

5. Richenbacher WE, Naka Y, Raines EP, Frazier OH, Couper GS, Pagani FD, et al. Surgical management of patients in the REMATCH trial. Ann Thorac Surg. 2003;75:S86-92.

6. Kavarana MN, Pessin-Minsley MS, Urtecho J, Catanese KA, Flannery $\mathrm{M}, \mathrm{Oz} \mathrm{MC}$, et al. Right ventricular dysfunction and organ failure in left ventricular assist device recipients: a continuing problem. Ann Thorac Surg. 2002;73:745-50.

7. Navia JL, McCarthy PM, Hoercher KJ, Smedira NG, Banbury MK, Blackstone EH. Do left ventricular assist device (LVAD) bridge-totransplantation outcomes predict the results of permanent LVAD implantation? Ann Thorac Surg. 2002;74:2051-62.

8. Blackstone EH, Lytle BW. Competing risks after coronary bypass surgery: the influence of death on reintervention. J Thorac Cardiovasc Surg. 2000;119:1221-30.

9. David HA, Moeschberger ML. The theory of competing risks. New York: Macmillan; 1978.

10. Blackstone EH, Naftel DC, Turner MEJ. The decomposition of timevarying hazard into phases, each incorporating a separate stream of concomittant information. J Am Stat Assoc. 1986;81:615-24.

11. Breiman L. Bagging predictors. Machine Learning. 1996;24:123-40.

12. Kalbfleisch JD, Prentice RL. The statistical analysis of failure time data. New York: Wiley; 1980.

13. Deng MC, Loebe M, El-Banayosy A, Gronda E, Jansen PG, Vigano M, et al. Mechanical circulatory support for advanced heart failure: effect of patient selection on outcome. Circulation. 2001;103: 231-7.

14. Pagani FD, Lynch W, Swaniker F, Dyke DB, Bartlett R, Koelling T, et al. Extracorporeal life support to left ventricular assist device bridge to heart transplant: a strategy to optimize survival and resource utilization. Circulation. 1999;100(suppl II):II206-10.

15. Ochiai Y, McCarthy PM, Smedira NG, Banbury MK, Navia JL, Feng J, et al. Predictors of severe right ventricular failure after implantable left ventricular assist device insertion: analysis of 245 patients. Circulation. 2002;106(suppl I):I198-202.

16. Granfeldt H, Koul B, Wiklund L, Peterzen B, Lonn U, Babic A, et al. Risk factor analysis of Swedish Left Ventricular Assist Device (LVAD) patients. Ann Thorac Surg. 2003;76:1993-9. 
17. Kirklin JK, Naftel DC, McGiffin DC, McVay RF, Blackstone EH, Karp RB. Analysis of morbid events and risk factors for death after cardiac transplantation. J Am Coll Cardiol. 1988;11:917-24.

18. Konstam MA, Cody RJ. Short-term use of intravenous milrinone for heart failure. Am J Cardiol. 1995;75:822-6.

19. Leprince P, Bonnet N, Rama A, Leger P, Bors V, Levasseur JP, et al. Bridge to transplantation with the Jarvik-7 (CardioWest) total artificial heart: a single-center 15-year experience. J Heart Lung Transplant. 2003;22:1296-303.

20. Dowling RD, Gray LA Jr, Etoch SW, Laks H, Marelli D, Samuels L, et al. Initial experience with the AbioCor implantable replacement heart system. J Thorac Cardiovasc Surg. 2004;127:131-41.

\section{Appendix}

Preoperative variables considered in analyses Demography: Age $(\mathrm{y})$, sex, body surface area $\left(\mathrm{m}^{2}\right)$, body mass index $\left(\mathrm{kg} \cdot \mathrm{m}^{-2}\right)$, weight $(\mathrm{kg})$, height $(\mathrm{cm})$.

Medical history: Diagnosis of heart disease, prior thoracic surgery, presence of implantable cardioverter-defibrillator.
Temporary support (within 3 days of implantation): Mechanical ventilation, intra-aortic balloon pump use, inotropic support, duration of pre-LVAD hospital stay (d).

Comorbidities (within 3 days of implantation): Acute myocardial infarction, infection, ventricular tachycardia or fibrillation.

Hemodynamics (immediately before implantation): Pulmonary artery systolic, diastolic, and mean pressures $(\mathrm{mm} \mathrm{Hg})$, cardiac index $\left(\mathrm{L} \cdot \min ^{-1} \cdot \mathrm{m}^{-2}\right)$, pulmonary vascular resistance (Wood units), central venous pressure $(\mathrm{mm} \mathrm{Hg})$, right ventricular stroke work index $\left(\mathrm{mm} \mathrm{Hg} \cdot \mathrm{mL} \cdot \mathrm{m}^{-2}\right)$ calculated from pulmonary artery (Swan-Ganz) data as follows:

$$
\begin{aligned}
R V S W I= & (\text { Mean pulmonary artery pressure } \\
& - \text { Mean right atrial pressure }) \cdot \text { Stroke volume index. }
\end{aligned}
$$

Laboratory values (1 day before implantation): Creatinine (mg . $\left.\mathrm{dL}^{-1}\right)$, total bilirubin $\left(\mathrm{mg} \cdot \mathrm{dL}^{-1}\right)$, aspartate transaminase $\left(\mathrm{U} \cdot \mathrm{L}^{-1}\right)$, total protein $\left(\mathrm{g} \cdot \mathrm{dL}^{-1}\right)$, albumin $\left(\mathrm{g} \cdot \mathrm{dL}^{-1}\right)$. 